\title{
Effects of MITC Released from Boscia Senegalensis as Biopesticide in Senegalese Seeds with Special Attention to Cowpea: Detection of Residues
}

\author{
Momar Talla GUEYE (Corresponding author) \\ Institut de Technologie Alimentaire, Hann-Dakar, BP 2765 - Sénégal \\ Université de Liège, Gembloux Agro-Bio Tech, Unité de Chimie Analytique, 2, Passage \\ des Déportés, 5030 Gembloux, Belgique
}

Tel: 32-2217-7635-3595 E-mail: gueyemt@gmail.com/mtgueye@ita.sn

\begin{abstract}
Abdoulaye DIALLO
Institut de Technologie Alimentaire, Hann, Dakar, BP 2765, Sénégal

E-mail: ablaye13@gmail.com

Younoussa DIALLO

Institut de Technologie Alimentaire, Hann, Dakar, BP 2765, Sénégal

E-mail: yunusdiallo@gmail.com
\end{abstract}

\section{Dogo SECK}

Centre Régional de Recherche en Ecotoxicologie et Sécurité Environnementale (CERES / Locustox), BP 3003 Dakar, Senegal

E-mail: dogoseck@orange.sn

Joeri VERCAMMEN

Interscience bvba, Avenue Jean-Etienne Lenoir 2-1348 Louvain-la-Neuve, Belgium E-mail: J.Vercammen@interscience.be 
Georges LOGNAY

Université de Liège, Gembloux Agro-Bio Tech, Unité de Chimie Analytique, 2, Passage des Déportés, 5030 Gembloux, Belgique

E-mail: Georges.Lognay@ulg.ac.be

Received: December 8, 2012 Accepted: January 21, 2013 Published: June 24, 2013

doi:10.5296/jee.v4i1.3903 URL: http://dx.doi.org/10.5296/jee.v4i1.3903

\begin{abstract}
B. senegalensis leaves and fruits are known to contain glucocapparin which hydrolysis by endogenous myrosinases lead to the release of methylisothiocyanate (MITC). This product is very active against insect stored products by fumigation. This paper reveals that MITC penetrate into seeds during treatment. Multiple Headspace Extraction coupled to GC (MHE-GC) method allowed to evaluate the level of MITC residues sequestrated by exposed seeds to B. senegalensis organs. Furthermore, tests conducted on germination capacity have been demonstrated that MITC doesn't corrupt the germination capacity of grains.
\end{abstract}

Keywords: Boscia senegalensis - MITC- seeds - MHE - residue - germination 


\section{Introduction}

Control of pests of stored product in Africa remains a challenge. The developed countries have proven techniques to reduce pest damages and losses to economically sustainable levels while the developing countries particularly western Africa still experience high post-harvest losses. Labeyrie (1982) reported that African farmers work for insects and the situation has not improved since. It is very uncommon to find recent studies on losses conducted in warehouses or farmers' granaries during storage, but it is generally accepted that losses due to insect pests can exceed 30\% (Ratnadass \& Sauphanor, 1989; Delobel \& Tran, 1993). Our observations show that Tribolium castaneum (Herbst) causes less loss to whole grain (Guèye and Delobel, 1999) since it prefers mostly the germs. Even the occurrence of a natural enemy of Prostephanus truncatus (Horn), Teretrius nigrescens (Lewis) in farmers' storage in Benin doesn't hamper damages caused by this pest, which stands at $44 \%$ in six months (Meikle et al., 2002). Laboratory evaluation showed that when maize was unprotected, damages and losses due to Sitophilus zeamais (Motschulsky) reached 20 and 40\% respectively in 4 and 8 months of storage (Guèye et al., 2012). For countries seeking to achieve food security in the light of climatic change (floods and droughts) and lack of storage infrastructure, these losses are major challenges in achieving the food security objective.

Products such as cowpea and groundnut remain important staple foods and cash crops. These have always suffered high pest damages by Caryedon serratus (Olivier) and Callosobruchus maculatus (Fabricius) during storage and can cause 80 to $100 \%$ losses within few months (Gomez, 2004; Amevoin et al., 2007). Groundnut is of high economic importance in Senegal where warehouse storage (called seccos) serves as a central storage. The control of insect pest of stored products (mainly C. serratus) was almost exclusively based on the use of fumigants (methyl bromide and phosphine) and insecticide dust. These grains were used often as seeds during the subsequent rainy season. However, at the individual level, farmers used any means available in the control of pests. Before the advent of pesticides, insecticidal plants and to a lesser extent inert dusts like ashes and sand were the main materials used for insect pest control. The success of pesticides during the three last decades has somewhat relegated the use of local materials. Lack of basic training, insufficient financial resources of farmers and numerous cases of poisoning and environmental hazards has drawn attention safety means of control pest (Guèye et al., 2011). Indeed, insecticidal plants in the local biodiversity are alternatives to synthetic chemical insecticides.

Many studies have been conducted on the basis of use of plants or extracts. High susceptibility of cowpea to bruchid vis-a-vis the role of cowpea in ensuring food security among rural populations has led to many of studies on this legume (Seck et al., 1993; Sanon et al., 2005; Doumma and Alzouma, 2008). Boscia senegalensis, a common plant from Senegal to the horn of Africa is very abundant in the Sahelian zone and has been widely used in this context (Baumer, 1995). Its efficacy due to glucocapparin hydrolysis by endogenous myrosinases (thioglucoside glucohydrolase, EC.3.2.3.1) which lead to the release of methylisothiocyanate (MITC) has been largely proven (Seck, 1994; Morra \& Borek, 2010). A study just carried out (Guèye et al., 2013) showed significant differences in glucocapparin level in leaves and fruits of B. senegalensis harvested in four localities of Senegal during two 
years. Additionally, it was revealed that during rainy season, plant parts showed lowest glucocapparin content but the maximum occurred two months later, in January. Previous studies have not investigated the occurrence of residues that may result from application of $B$. senegalensis to stored seeds. MITC is known to have insecticidal, nematicidal and fungicidal properties (Wales, 2002). When liberated from pesticide precursors as metam sodium and dazomet (Zheng et al., 2006), it is also considered as an atmospheric, aqueous and soil contaminant and has a respiratory and eye irritant actions (Dourson et al., 2010; Swancutt et al., 2010).

The aim of this work is to evaluate occurrence of MITC in cowpea and other cereal and legume seeds treated with B. senegalensis. We also detect the ability of seeds to germinate after exposure of increasing doses of MITC derivated from B. senegalensis crushed leaves and fruits.

\section{Materials and Methods}

\subsection{Plant Material}

\subsubsection{The Substrates}

These were cowpea (Vigna unguiculata L. (Walp)), maize (Zea mays L.), millet (Pennisetum typhoides L.) and peanut (Arachis hypogaea Ol.). Seeds were sieved to remove immature seeds and foreign material. To eliminate hidden infestation, seeds were kept in the freezer for a week before use.

\subsubsection{Boscia Senegalensis}

Fruits and green leaves of $B$. senegalensis were harvested at Dakar. Harvest was always done early in the morning and plants immediately tested on insects. Germination tests and determination of quantities of MITC were carried out on the same batches of biological material (seeds).

material (seeds).

\subsection{Experimental Procedure}

\subsubsection{Germination Tests}

For each dose, germination tests were performed at the end of the treatment. Three controls were treated under the same conditions. 100 seeds were randomly placed on water-soaked cotton spread in a Petri dish of $12 \mathrm{~cm}$ diameter. The experiment was replicated 3 times and germination rate calculated after 10 days. Other trials were conducted with cowpea which had been stored for two years with the treatment of B. senegalensis leaves at the rate $2 \mathrm{~g}$ of leaves/100g of cowpea. Results were subjected to ANOVA using the Minitab 16 Statistical Software. Differences between treatments were determined by multiple comparisons using the Tukey test at $\mathrm{P}<0.05$. 


\subsubsection{Analytical Standards}

A 4-point calibration curve was constructed for MITC under MHE conditions (see below). MITC (97\%) was purchased from Sigma Aldrich (Bornem, Belgium). MITC spike solutions were prepared in diethyl ether at $0.01 \mathrm{mg} / \mathrm{ml}, 0.1 \mathrm{mg} / \mathrm{ml}, 1 \mathrm{mg} / \mathrm{ml}$ and $10 \mathrm{mg} / \mathrm{ml}$, respectively. Actual analytical standards were obtained by spiking $100 \mu \mathrm{L}$ of the respective MITC spike solution onto a small piece of filter, which was contained in a $20 \mathrm{~mL}$ headspace vial containing $1 \mathrm{~g}$ of untreated seeds (with screw cap and PTFE lined septum). In order to assist ether evacuation, the vial was kept open to air for $2 \mathrm{~min}$. Final concentration levels on filter were $1 \mu \mathrm{g}, 10 \mu \mathrm{g}, 100 \mu \mathrm{g}$ and $1000 \mu \mathrm{g}$. Toluene-D8 was used as reference standard to normalize MITC peak area prior to MHE data processing.

\subsubsection{Quantification of Residues}

Residual MITC in both leaves and fruits treated grains was determined using multiple headspace extraction (MHE) in combination with GC/MS in full scan and SIM mode. Plants were treated with both fruits and leaves of B. senegalensis. Approximately $4 \mathrm{~g}$ of either fruits or leaves were mixed with $100 \mathrm{~g}$ plant material. Final amounts were between 2 and $2.5 \mathrm{~g}$. Residues concentrations are expressed in mg residual MITC per g.

A Thermo Scientific Trace 1300 GC instrument (Interscience, Louvain-la-Neuve, Belgium), equipped with Thermo Triplus RSH autosampler and i-connect S/SL injector module, was hyphenated to a Thermo ISQ single quadrupole MS. The autosampler was fitted with MHE vent tool. Separation was achieved using a $20 \mathrm{~m} \times 0.18 \mathrm{~mm}$ I.D., $1 \mu \mathrm{m}$ df Rxi-624 Sil MS capillary column (Restek, Bellefonte, PA, USA). Experimental details are summarized in Table 1.

\section{Results}

\subsection{Evaluation of Germination Rate of Boscia Senegalensis Treated Seeds}

The experiment showed that such treatment using crushed B. senegalensis leaves and fruits over ten days does not have a significant effect in exposed seeds to MITC liberated from glucocapparin $(\mathrm{P}<0.05)$. High levels of germination were recorded with millet, cowpea, groundnut and maize regardless concentration (table 2). Another experiment with cowpea kept during 24 months gave a germination rate of $84 \pm 6 \%$.

\subsection{Quantification of Residual MITC in Cowpea}

Table 3 shows parameters of linear regression derived from cowpea treated with $B$. senegalensis fruits and leaves and total amount of MITC found in their two organs. Concentrations of MITC were four times high in fruits $(2.03 \mathrm{mg} / \mathrm{g})$ than in leaves $(0.55 \mathrm{mg} / \mathrm{g})$.

Figure 1 and 2 described plot of data and linear regression fit of B. senegalensis fruits and leaves, respectively. Based on triple replications, fruits and leaves has the same $\mathrm{R}^{2}=0.9865$.

Figure 3 depicts the full scan chromatogram. Insert shows the ion trace extracted at $m / z=73$, which is typical for MITC. A least, three other main peaks were also identified: unknown molecule at $2.33 \mathrm{~min}$, Ethyl acetate (3.91 $\mathrm{min}$ ) and Hexenal (5.98 $\mathrm{min}$ ). 


\section{Discussion}

The results presented herein showed the release of MITC by B. senegalensis fruits and leaves similar to the observation of Seck (1994). However, concerning sequestration of MITC by seeds subjected to $B$. senegalensis, information is limited. For the past two decades that $B$. senegalensis had been studied, only Sanon's et al. (2005) had conducted studies related to MITC liberated by $B$. senegalensis. Judging from the difference between the amount of MITC introduced into jar and the remaining after the experiment, they suggested that MITC was absorbed by cowpea seeds. In our study, natural MITC directly produced by $B$. senegalensis raw material was measured after 10 days exposure using the MHE method. It has been proved that all seeds tested namely, millet, maize, cowpea and groundnuts have sequestered MITC. Using a simple method, comprising aeration of seeds treated for 24 hours at $30^{\circ} \mathrm{C}$ to liberate the MITC molecule, still revealed significant amounts of MITC in all types of media. This is due to the fact that boiling point of MITC is high $\left(118^{\circ} \mathrm{C}\right)$. Thus, it appeared important to establish kinetic desorption of MITC over time in all these kinds of seeds. This is because composition and texture are different for different seed types; for example high seed oil content would have greater influence on MITC liberation.

As a result, larvae of stored grain products such as P.truncatus, C. maculatus, C. serratus and $S$. zeamais can be controlled by MITC. Nevertheless, the appropriate level of sequestration and time of exposure should be determined for efficiency in the control. Indeed, an ongoing study being undertaken to determine the efficacy of $B$. senegalensis against major insect pests of stored products of legumes and cereals revealed that efficient doses required to kill adults will require twofold or forthfold increases, depending on insect species, (Guèye et al., Unpublished results).

Tests conducted on germination demonstrated that MITC doesn't disrupt the germination capacity of seeds. No significant statistical difference was found between control and treated seeds with doses of $B$. senegalensis. Furthermore with cowpea seeds treated with $B$. senegalensis, leaves kept in an incubator at $30^{\circ} \mathrm{C}$ during 24 months, had the same level of germination as the control $(84 \pm 6 \%)$. On the basis of germination rate, Kéita et al. (2002) did not find significant effect with seeds treated with aromatized powder of Ocimum basilicum and $O$. gratissimun after 5 days exposure (88\%). Indeed, low level of emergence rate is a major concern of smallholder farmers in Senegal largely due to insect pest attacks during storage.

According to the MHE investigation, further studies are necessary to determine the level of MITC residues in food prepared from $B$. senegalensis (fruits and leaves) protected grains. It is also strongly recommended to measure MITC in all B. senegalensis based edible products before use as food. Currently in Niger, several products from B. senegalensis are being developed for human consumption with intensive promotion going on. In this context, the measurement of residual MITC is essential for determining food safety status. The MHE method reported in this paper could be systematically carried out. 


\section{References}

Amevoin, K. Sanon, A., Apossaba, M., \& Glitho I. A. (2007). Biological control of bruchids infesting cowpea by the introduction of Dinarmus basalis (Rondani) (Hymenoptera: Pteromalidae) adults into farmers stores in West Africa. Journal of Stored Products Research 43, 240-247. http://dx.doi.org/10.1016/j.jspr.2006.06.004.

Baumer, M. (1995). Arbres, arbustres et arbrisseaux nourrissiers en Afrique occidentale. Dakar, Enda-Editions, Séries Etudes et Recherches N 168-169-170, 260 p.

Doumma, A., \& Alzouma, I. (2008). Influence de Boscia senegalensis (pers) Lam ex Poir. (Capparaceae) sur les capacités de dispersion de Dinarmus basalis Rond. (Hymenoptera Pteromalidae) dans les systèmes de stockage traditionnels du niébé. $8^{\text {ème }}$ Conférence Internationale sur les ravageurs en agriculture, Montpellier 22 et 23 octobre 2008.

Dourson, M. L., Kohrman-Vincent, M. J., \& Allen, B. C. (2010). Dose response assessment for effects of acute exposure to methyl isothiocyanate (MITC). Regulatory Toxicology and Pharmacology, 58, 181-188. http://dx.doi.org/10.1016/j.yrtph.2010.04.006

Gomez, C. (2004). Cowpea: Post-harvest operations. Food and Agriculture Organization of the Unites Nations (FAO), Rome, Italy, 70. Retrieved from http://www.fao.org/fileadmin/user_upload/inpho/docs/Post_Harvest_Compendium-Cowpeas. pdf

Guèye, M. T., \& Delobel, A. (1999). Relative susceptibility of stored pearl millet products and fonio to insect infestation. Journal of Stored Products Research, 35, 277-283. PII: S00 2 2- 47 4X(9 9 )000 1 1- 9

Guèye, M. T., Seck D., Diallo, A., Trisman, D., Fischer, C., Barthelemy J-P., Wathelet, J-P., Lognay, G., 2013. Development of a performant method for glucocapparin determination in Boscia senegalensis Lam Ex. Poir.: a study of the variability. American Journal of Analytical Chemistry 4, 104-110. doi:10.4236/ajac.2013.42014.

Guèye, M. T., Cissokho, P. S., Goergen, G., Ndiaye, S., Seck, D., Guèye G., Wathelet, J. P., \& Lognay, G. (2012). Efficacy of powdered maize cobs against the maize weevil Sitophilus zeamais (Coleoptera: Curculionidae) in stored maize in Senegal. International Journal of Tropical Insect Science, 32(2), 94-100. http://dx.doi.org/10.1017/S1742758412000148

Guèye, M. T., Seck, D., Bâ, S., Hell K., Sembène, M., Wathelet, J. P., \& Lognay, G. (2011). Insecticidal activity of Boscia senegalensis (Pers.) Lam ex Poir. on Caryedon serratus (O1.) pest of stored groundnuts. African Journal of Agricultural Research, 6(30), 6348-6353. http://dx.doi.org/10.5897/AJAR11.949

Labeyrie, V. (1992). Problèmes fondamentaux posés par les insectes des denrées. In Actes du seminaire international à Abidjan, 29 jan.-1 fev. 1999. Ed. K. Foua-Bi \& B. J. R. Philogène : 9-14.

Meikle, W. G., Markham, R. H., Nansen, C., Holst, N., Degbey, P., Azoma, K., \& Korie, S. (2002). Pest management in traditional maize stores in West Africa: a famer's perspective. $J$. 
Econ. Entomol, 95(5), 1079-1088.

Morra, M. J., \& Borek, V. (2010). Glucosinolate preservation in stored Brassicaceae seed meals. Journal of Stored Product Research, 46, 98-102. http://dx.doi.org/10.1016/j.jspr.2009.12.001

Ratnadass, A., \& Sauphanor, B. (1989). Les pertes dues aux insectes sur les stocks paysans de céréales en Côte d'ivoire. Céréales en régions chaudes, AUPELF-UREF, Ed John L ibbey Eurotext, Paris , pp.141-150.

Sanon, A., Sou, S., Dabiré, C., Ouedraogo, A. P., \& Huignard J. (2005). Combining Boscia senegalensis Lamarck (Capparaceae) leaves and augmentation and the larval parasitoid Dinarmus basalis Rondani (Hymenoptear: Pteromalidae) for bruchids control in stored $\begin{array}{llll}\text { cowpea. Journal of } & \text { Entomology, } & \text { 40-45, }\end{array}$ http://dx.doi.org/10.1016/j.biocontrol.2006.09.012

Seck, D. (1994). Développement de méthodes alternatives de contrôle des principaux insectes ravageurs des denrées emmagasinées au Sénégal par l'utilisation de plantes indigènes. Thèse de doctorat: Faculté des Sciences Agronomiques de Gembloux, Belgique.

Seck, D., Lognay, G., Haubruge, E., Wathelet, J. P., Marlier, M., Gaspar, C., \& Severin M. (1993). Biological activity of the shrub Boscia senegalensis (Pers.) Lam ex Poir. (Capparaceae) on stored grain insects. Journal of Chemical Ecology, 19(2).

Swancutt, K. L., Dail, M. K., Mezyk, S. P., \& Ishida, K. P. (2010). Absolute kinetics and reaction efficiencies of hydroxyl-radical-induce degradation of methyisothiocyante (MITC) in different quality waters. Chemosphere, 81, 339-344. http://dx.doi.org/10.1016/j.chemosphere.2010.07.027

Wales, P. C. (2002). Evaluation of Methyl Isothiocyanate as a toxic air contaminant. Par A Environmental fate. California Environmental Protection Agency Sacramento, California, 16.

Zheng, W., Yates, S. R., Papiernik, S. K., \& Nunez, J. (2006). Conversion of metam sodium and emission of fumigant from soil columns. Atmospheric Environment, 40, 7046-7056. http://dx.doi.org/10.1016/j.atmosenv.2006.06.009

Table 1. Overview of experimental settings

\begin{tabular}{|l|l|}
\hline Parameters & Settings \\
\hline MHE method & \\
\hline Incubation time & $5.00 \mathrm{~min}$ \\
\hline Incubation temperature & $150^{\circ} \mathrm{C}$ \\
\hline Injection volume & $1 \mathrm{~mL}$ \\
\hline \# Extractions & 3 \\
\hline GC method & \\
\hline GC oven & $35^{\circ} \mathrm{C}(5.00 \mathrm{~min}) \rightarrow 175^{\circ} \mathrm{C}(0.00 \mathrm{~min}) @ 20^{\circ} \mathrm{C} / \mathrm{min}$ \\
\hline S/SL temperature & $240^{\circ} \mathrm{C}$ \\
\hline Split flow & $15 \mathrm{~mL} / \mathrm{min}$ \\
\hline
\end{tabular}




\begin{tabular}{|l|l|}
\hline Carrier gas & Helium @ $1.5 \mathrm{~mL} / \mathrm{min}$ \\
\hline MS method & \\
\hline Mode & Full scan \\
\hline Mass range & $29-400 \mathrm{amu}$ \\
\hline Scan time & $0.2 \mathrm{sec}$ \\
\hline
\end{tabular}

Table 2. Germination of seed treated with Boscia senegalensis fruits (Fr) and leaves (L). Tests showed any difference between controls and treated seeds $(n=300 ; P<0.05)$.

\begin{tabular}{|c|l|l|l|l|l|}
\hline Doses $(\mathrm{g} / \mathrm{l})$ & & Peanut & Niebe & Maize & millet \\
\hline \multirow{3}{*}{0.5} & Fr & $87 \pm 2$ & $96 \pm 3$ & $87 \pm 3$ & $83 \pm 3$ \\
\cline { 2 - 6 } & L & $92 \pm 3$ & $98 \pm 0$ & $87 \pm 11$ & $80 \pm 2$ \\
\hline \multirow{3}{*}{1} & Fr & $91 \pm 4$ & $96 \pm 3$ & $91 \pm 1$ & $84 \pm 4$ \\
\cline { 2 - 6 } & L & $87 \pm 1$ & $94 \pm 5$ & $87 \pm 11$ & $81 \pm 1$ \\
\hline \multirow{3}{*}{2} & Fr & $88 \pm 5$ & $94 \pm 4$ & $82 \pm 15$ & $84 \pm 4$ \\
\cline { 2 - 6 } & L & $85 \pm 4$ & $96 \pm 2$ & $88 \pm 7$ & $82 \pm 3$ \\
\hline \multirow{2}{*}{3} & Fr & $83 \pm 4$ & $97 \pm 3$ & $78 \pm 11$ & $87 \pm 3$ \\
\cline { 2 - 6 } & L & $85 \pm 3$ & $97 \pm 1$ & $87 \pm 6$ & $77 \pm 1$ \\
\hline \multirow{2}{*}{4} & Fr & $86 \pm 6$ & $95 \pm 4$ & $92 \pm 2$ & $83 \pm 4$ \\
\cline { 2 - 6 } & L & $87 \pm 4$ & $98 \pm 1$ & $88 \pm 1$ & $84 \pm 2$ \\
\hline
\end{tabular}


Table 3. Results from linear regression of Boscia senegalensis fruits and leaves and quantities of MITC

\begin{tabular}{|l|c|c|}
\hline & Fruits & Leaves \\
\hline Area & & 1183152 \\
\hline $\mathbf{0}$ & 4683253 & 1147657 \\
\hline $\mathbf{2}$ & 4542755 & 1124704 \\
\hline F & 4451900 & 73.197 \\
\hline df & 73.197 & 1 \\
\hline MITC $(\mathrm{mg} / \mathrm{g})$ & 1 & 0.55 \\
\hline
\end{tabular}

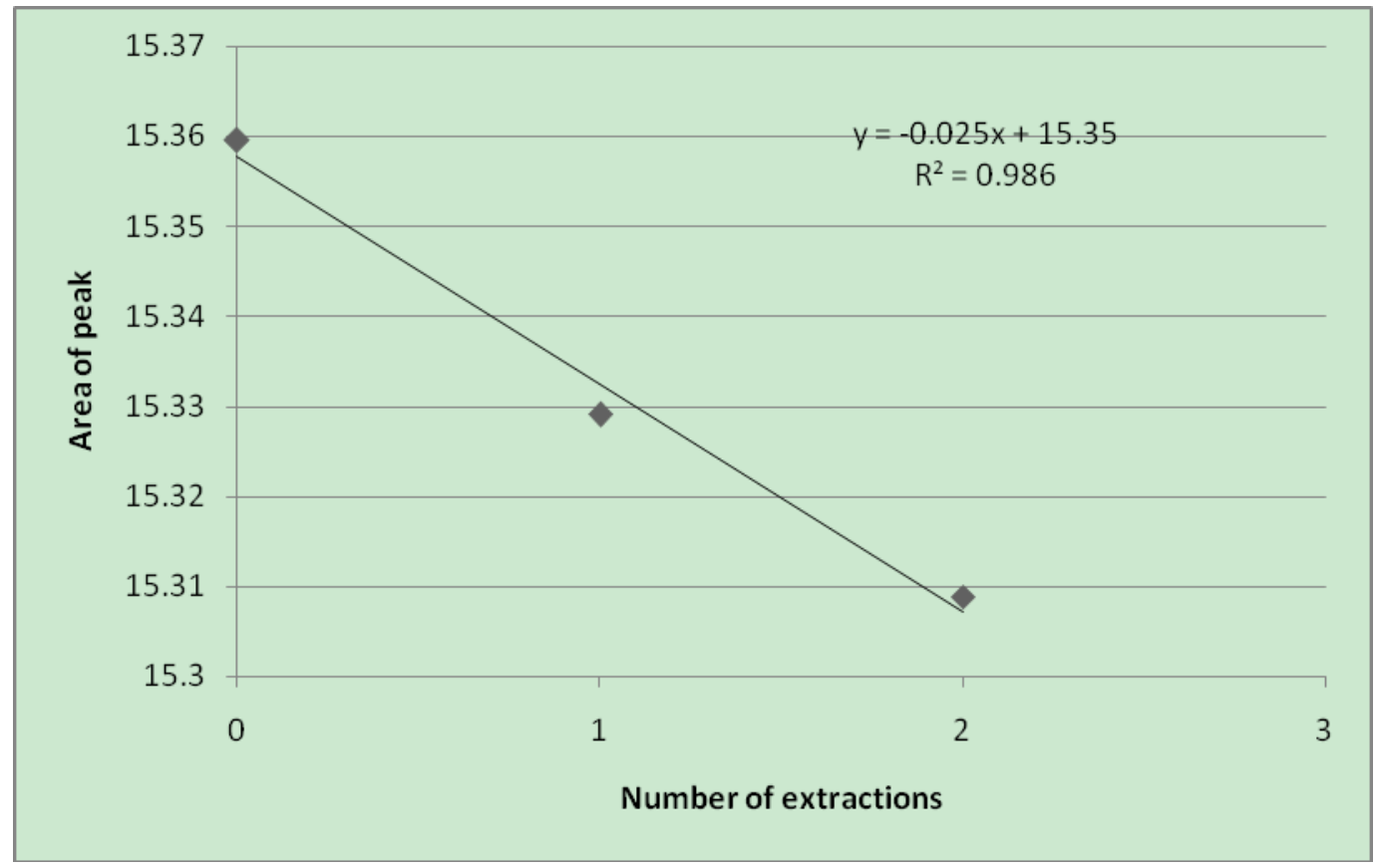

Figure 1. Plot of data and of linear regression fit for MITC from Boscia senegalensis fruits by MHE 


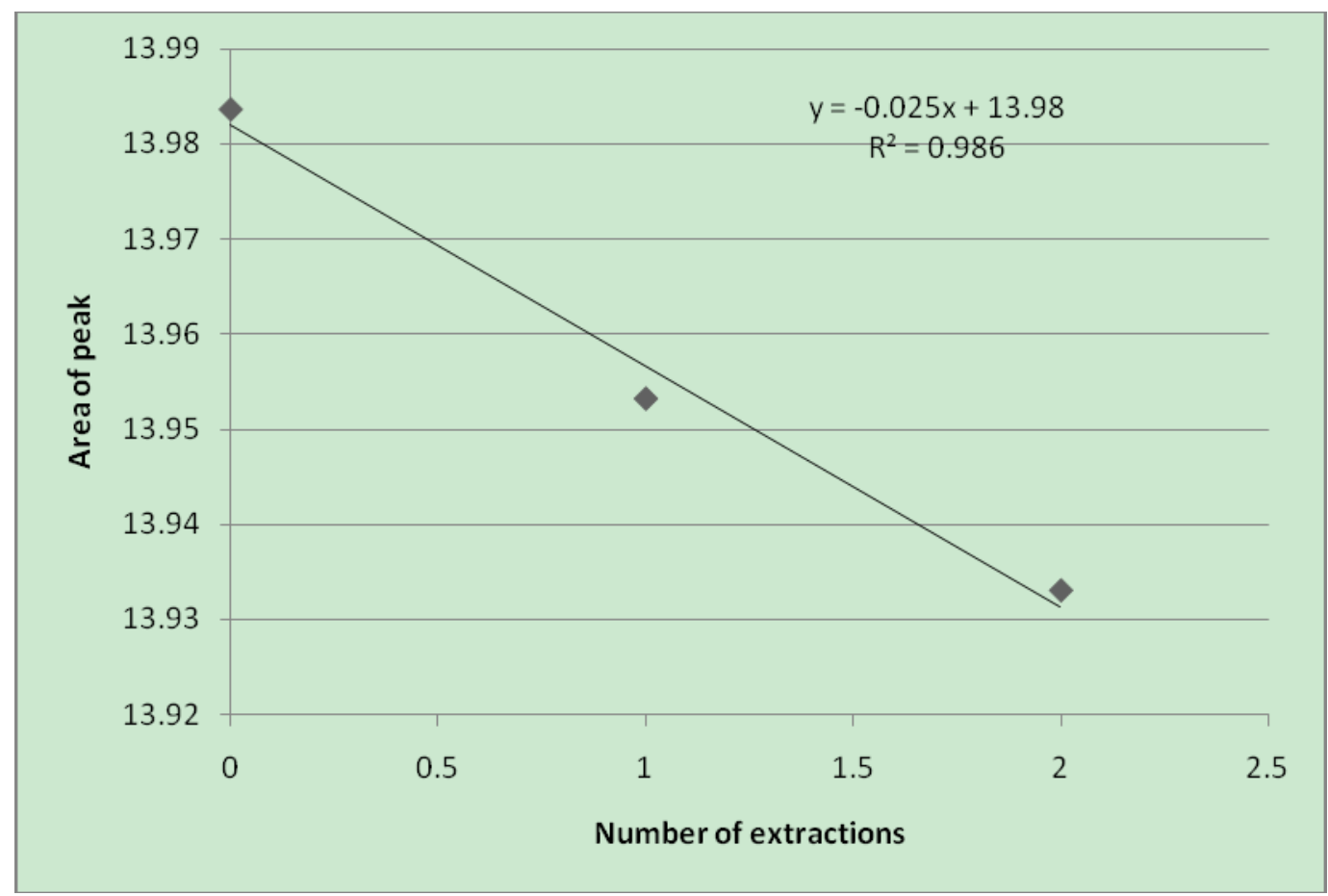

Figure 2. Plot of data and of linear regression fit for MITC of Boscia senegalensis leaves by MHE

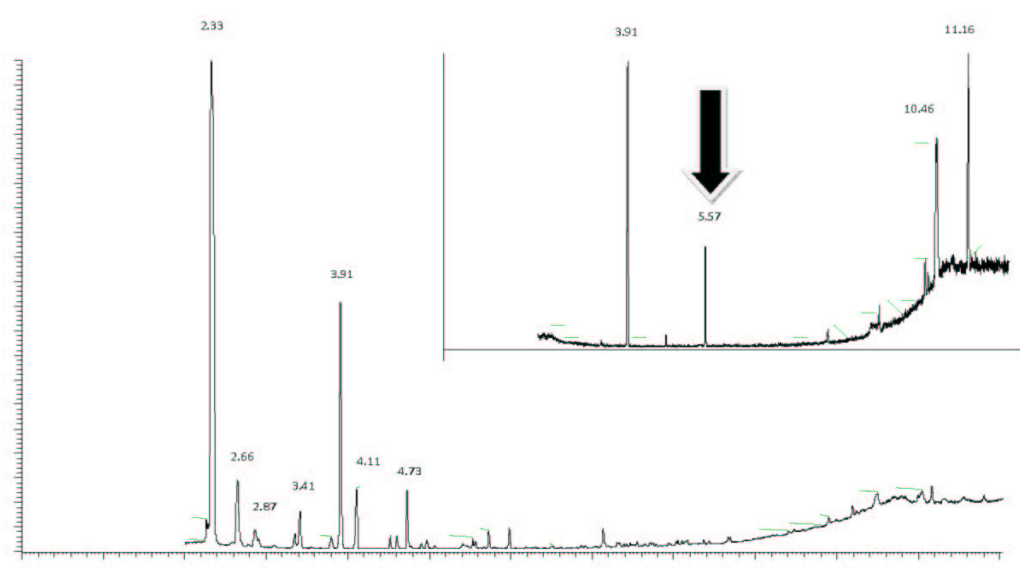

Figure 3. Chromatogramm of cowpea with MITC (arrow with the insert - RIC on $m / z=73$ ) 